\title{
Possibilities and limitations of radioimmunoscintigraphy and conventional diagnostic modalities in choroidal melanoma
}

\author{
D F Schaling, J A Oosterhuis, M J Jager, H Kakebeeke-Kemme, E K J Pauwels
}

Department of Ophthalmology, University Hospital, Leiden, Netherlands D F Schaling J A Oosterhuis $M$ J Jager

H Kakebeeke-Kemme

FC Donders Institute of Ophthalmology, University Hospital Utrecht, Netherlands D F Schaling

Department of Diagnostic Radiology, Division of Nuclear Medicine, Leiden University Hospital, Leiden, Netherlands E K J Pauwels

Correspondence to: D F Schaling, MD FC Donders Institute of Ophthalmology, University Heidelberglaan 100, Utrecht Heidelberglaa

Accepted for publication 26 October 1993

\begin{abstract}
A prospective clinical study to assess the value of immunoscintigraphy with a monoclonal antibody (MoAb) against high molecular weight melanoma associated antigen (225.28S) was performed in 43 patients with choroidal melanoma; in six patients with a lesion suspected of being choroidal melanoma, and in seven patients with a benign lesion simulating a choroidal melanoma. The results of immunoscintigraphy in choroidal melanoma were compared with results of conventional diagnostic modalities like ultrasonography and fluorescein angiography. Planar scintigraphy showed a detection rate of $49 \%$ which is comparable with other studies. The detection with scintigraphy was correlated to the size of the choroidal melanoma. The use of single photon computed tomography did not increase the sensitivity of immunoscintigraphy. Ultrasonography yielded a correct diagnosis in 37 of 42 melanomas (88\%). With fluorescein angiography a correct diagnosis was obtained in 11 of 30 melanomas (36.6\%). The value of immunoscintigraphy with MoAb 225.28S in small choroidal melanomas is limited; its reliability increases in large tumours. Immunohistochemistry with MoAb 225.28S showed antigen expression in $95 \%$ of the stained tissue specimens of choroidal melanoma.
\end{abstract}

(Brf Ophthalmol 1994; 78: 244-248)

Although the introduction of standardised A and B scan ultrasonography ${ }^{1}$ made the diagnosis of choroidal melanoma much more reliable, the correct diagnosis in small intraocular lesions remains a clinical challenge. The tissue reflectivity, assessed by A scan ultrasonography cannot be determined accurately in intraocular lesions with little prominence.

The introduction of the hybridoma technique of Kohler and Millstein provided the possibility of selection and production of monoclonal antibodies (MoAbs) against any tissue antigen. ${ }^{2}$ The availability of MoAbs to cutaneous melanoma, which cross react with choroidal melanoma, stimulated us to investigate the value of these immunological tools labelled with a radioactive tracer for diagnostic immunoscintigraphy in choroidal melanoma. Immunohistochemical pilot studies revealed adequate reactivity of cutaneous anti-melanoma antibodies directed to the high molecular weight melanoma associated antigen (HMW-MAA) in choroidal melanoma tissue. $^{34}$

The aim of the present prospective clinical study was to assess the value of immunoscintigraphy as a diagnostic test in choroidal melanoma in comparison with other diagnostic tests and to study the expression of the HMW-MAA in choroidal melanoma in relation to the scintigraphic results with the HMW-MAA antibody.

\section{Material and methods \\ PATIENTS}

Between 1988 and 1992, 56 patients with a lesion suspected of being melanoma were referred to the Department of Ophthalmology for ophthalmoscopic examination, ultrasonography, fluorescein angiography, and immunoscintigraphy with technetium-99m labelled MoAb 225.28S. Informed consent for the immunoscintigraphic study was obtained from all patients. The patient group consisted of 32 women and 24 men, aged 24-87 years (mean age 63.5). From the results of ophthalmoscopy, ultrasonography, and fluorescein angiography a lesion was classified as a melanoma, as suspected of being a melanoma, or as a lesion other than a melanoma.

ULTRASONOGRAPHY

Standardised ultrasonography was performed with a Triscan (Biophysic Medical SA, Clermont Ferrand, France) to determine the internal reflectively of a lesion and to obtain a two dimensional image of the intraocular lesion.

The prominence and the diameter of a lesion were also determined by ultrasonography and the tumour was classified according to the TNM classification of the International Union against Cancer. ${ }^{5}$

\section{FLUORESCEIN ANGIOGRAPHY}

Fluorescein angiography was performed to detect typical fluorescein angiographic features which can be seen in choroidal melanoma such as a hyperfluorescent zone surrounding the tumour and focal pinpoint hyperfluorescence on the edge 
of a lesion. ${ }^{6}$ If fluorescein angiography showed hyperfluorescence but not the characteristic pattern of hypo- and hyperfluorescence the diagnosis was given as suspected of being a melanoma. Fluorescein angiograms were judged by an ophthalmologist experienced in fluorescein angiography who was not aware of the clinical findings.

\section{IMMUNOSCINTIGRAPHY}

Monoclonal antibody 225.28 S against a high molecular weight melanoma associated antigen (HMW-MAA) was labelled with $740 \mathrm{mBq}$ technetium. The antibody was produced in mice and provided as an instant labelling kit (Technemab$\mathrm{K}-1$; Sorin Biomedica, Italy). Four hundred mg of potassium perchlorate was given orally to protect the thyroid from radiation due to unbound technetium, 30 minutes before a slow, 2 minute intravenous injection of the antibody (350 $\mu$ g protein).

For more detailed information on the immunoscintigraphic procedure we refer to a previous publication. ${ }^{7}$ The interpretation of the scans was made by a nuclear physician who was unaware of the localisation of the tumour. A scintigraphic result was given as positive, negative, or doubtful. A doubtful result is defined as a trace of activity on one side which cannot be judged as positive. Measurements with a double pinhole collimator were carried out to quantify the radioactivity and to achieve an increase in detection rate. ${ }^{7}$ The measurements were performed immediately after the whole body scans 6 hours after injection. The ratios of the counts of the left and the right eye at 6 hours post injection were calculated. Variance analysis was used to determine the significance of differences in counts between both eyes.

During the course of this study it was decided to perform single photon emission computed tomography (SPET) in case of a negative or doubtful result with planar scintigraphy. SPET gives a reconstructed image which may help to detect tumours not visualised with planar scintigraphy. SPET aquisition was carried out at 6 hours after administration. The same gammacamera and collimator were used as for the planar images. The patient was placed in a supine position and 60 views of 30 seconds were taken over a $360^{\circ}$ rotation in a $128 \times 128$ matrix. Horizontal slices were reconstructed by means of filtered back projection using a Shepp and Logan filter. Subsequently, coronal slices were calculated. In all cases the slice thickness was 2 pixels - that is, $5.4 \mathrm{~mm}$. SPET is useful to visualise nasally localised tumours which may be obscured by a specific background activity in the nasopharynx region. ${ }^{89}$ Therefore a possible corelation between tumour location and detectability with SPET was investigated. Results of SPET were given according to the same criteria as planar scintigraphy.

The melanomas were divided according to their localisation in the eye. The following localisations were used: (1) posterior pole and peripapillary area, (2) temporal periphery, (3) nasal periphery, (4) peripheral 6 and 12 o'clock position.

\section{IMMUNOHISTOCHEMISTRY}

The expression of the melanoma associated antigen was assessed with MoAb 225.28S in 22 melanoma tissue specimens obtained from patients in the present study. Tissue specimens were obtained immediately after enucleation and snap frozen in OCT compound embedding medium (Tissue Tek, Miles Inc, Elkkart, IN, USA) and stored at $-70^{\circ} \mathrm{C}$. For the immunohistochemical staining procedure we refer to a previous publication. ${ }^{10}$ The percentage of positively staining tumour cells was assessed by light microscopy by two investigators independently. The results deviated by $10 \%$ maximally, and average scores were used in the calculations. In some cases assessment of staining percentages was impossible owing to heavy pigmentation of tumour tissue.

ANALYSIS OF THE DATA

For statistical analysis of the results the McNemar test, $\chi^{2}$ test, variance analysis, and Kendall $\tau$ correlation test were used. Differences between results of different diagnostic modalities were regarded as significant at $\mathrm{p}$ values of $<0.05$.

\section{Results}

\section{CLINICAL DIAGNOSIS}

Based on clinical investigation 43 of 56 patients had a choroidal melanoma and six patients had a lesion suspected of being a melanoma. Seven patients had a benign lesion, two a choroidal naevus, two hyperplasia of the pigment epithelium, two exudative macular degeneration, and one a chorioretinal scar. One of the patients with melanoma had a choroidal naevus in the fellow eye. In 31 patients with a choroidal melanoma, therapy consisted of enucleation of the tumour bearing eye. Twelve patients were treated with $\beta$ irradiation by means of a ruthenium-106 applicator. In the six patients with a suspicious lesion ophthalmoscopic control and ultrasonography are performed at regular intervals.

\section{HISTOLOGY}

Of the enucleated eyes nine melanomas were of the spindle cell type, three of the epitheloid cell type, and 15 tumours were of mixed cell type. The cell type could not be obtained in three cases. One eye did not contain a choroidal melanoma but a large haemorrhage. Scrutiny of the data of this patient, who was referred to our clinic for immunoscintigraphy, revealed a negative result on immunoscintigraphy but the ultrasonographic result was interpreted as a melanoma by an inexperienced physician. The mean tumour prominence of the whole group of melanomas was $5.2 \mathrm{~mm}$. Lesion prominence varied from 1 to $15 \mathrm{~mm}$.

\section{RADIOIMMUNOSCINTIGRAPHY}

Planar scintigraphy was performed in 43 patients with melanoma; SPET was performed additionally in 17 patients. With planar scintigraphy an increased uptake of radioactivity in the 
melanoma bearing eye was found in 21 of 43 cases (sensitivity $49 \%$ ). In the first 16 patients of the study the double pinhole measurements showed a significantly higher activity in the tumour bearing eye in 13 cases (81.3\%). However, double pinhole measurements in patients with melanoma simulating lesions showed left/right differences in four of eight cases.

SPET yielded a positive result in nine of 17 cases ( $53 \%$ sensitivity). In two melanomas a dubious increase of activity was shown, and in six cases of melanoma a negative result with SPET was obtained. In the patient with a haemorrhage planar scintigraphy and pinhole scintigraphy yielded a negative result.

In eight patients with benign intraocular lesions one showed an increased uptake in the fellow eye on planar scintigraphy, the other scintigrams were negative. In five control patients four SPET images were negative and one SPET image showed dubious increased uptake. SPET showed uptake once in the contralateral eye of a patient with a lesion suspected of being a melanoma, thus suggesting the presence of a melanoma in the contralateral eye (Figs 1 and 2).

Detection on planar scintigraphy related to melanoma size is shown in Table 1 . A significant correlation between tumour size (TNM classification) and detection rate was found (Kendall's $\tau$ correlation procedure, $\mathrm{p}<0.0008)$. No preferential localisation of the tumours could be assessed in the groups of tumours detected by planar scintigraphy or SPET.

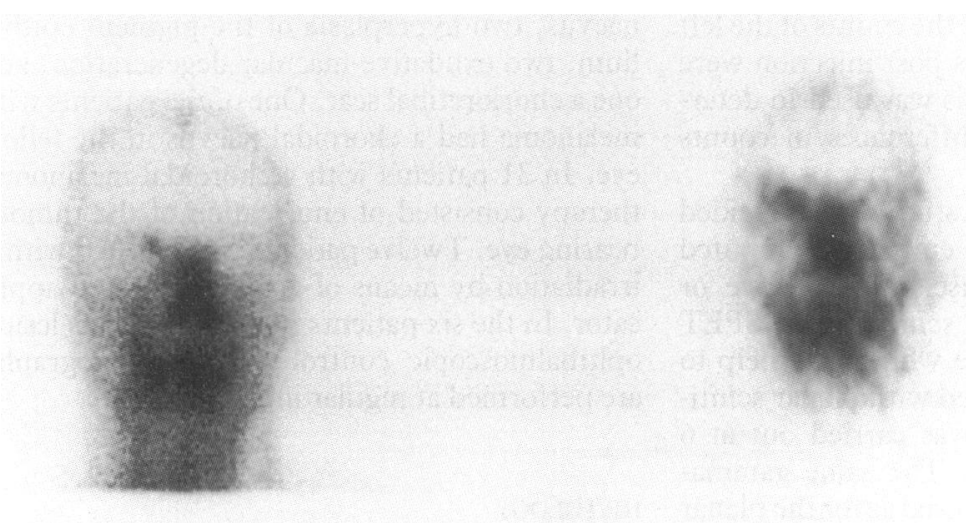

Figure 1 Planar scintigram and single photon emission tomogram showing increased activity in the right eye (melanoma right eye).

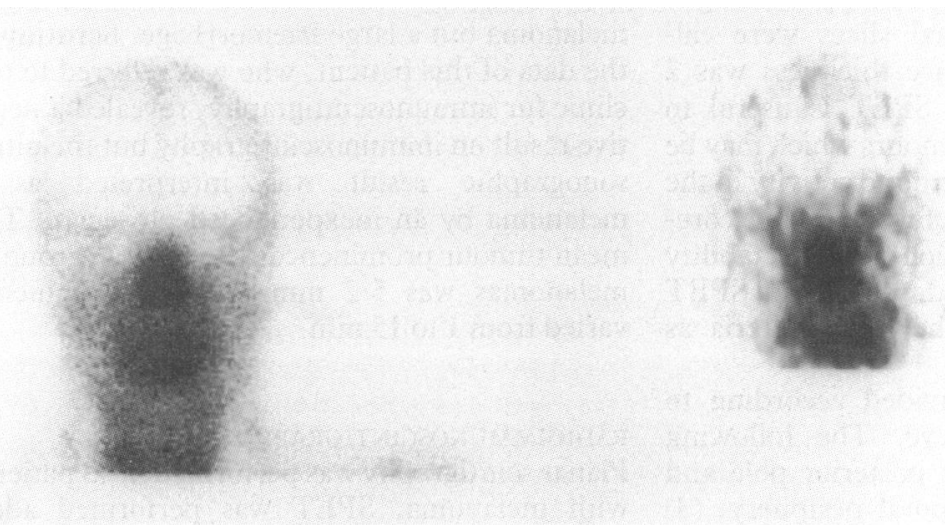

Figure 2 Planar scintigram showing equal activity in left and right orbit and single photon emission tomogram showing dubious increase of activity in the left orbit (control patient).
The group of tumours detected by planar scintigraphy had a mean maximal diameter of $14 \cdot 2(\mathrm{SD} 3 \cdot 0) \mathrm{mm}$ and a mean prominence of $7 \cdot 3$ (SD 3.7) $\mathrm{mm}$. The group of tumours not detected by scintigraphy has a mean maximal diameter of $11 \cdot 0(\mathrm{SD} 2 \cdot 0) \mathrm{mm}$ and a mean prominence of $4 \cdot 7$ $(\mathrm{SD} 2 \cdot 4) \mathrm{mm}$. The differences between the mean maximal diameter of both groups ( $p$ value $<0.0004)$ and the mean prominence of both groups ( $\mathrm{p}$ value $<0.001$ ) are significant (variance analysis). Mean prominence of the melanomas detected and not detected by SPET did not differ significantly (6.0 mm $v 6.3 \mathrm{~mm})$.

\section{ULTRASONOGRAPHY}

With ultrasonography 37 of 42 melanomas were correctly diagnosed $(88 \%)$. In the remaining five cases a melanoma was suspected (Table 2 ). With regard to tumour size the results are as follows: three of five $\mathrm{T} 1$ classified tumours could be classified correctly $(60 \%), 14$ of $16 \mathrm{~T} 2$ classified tumours could be classified correctly ( $88 \%)$, and 20 of 21 T3 classified tumours were classified correctly $(95 \%)$. There were no false positive or false negative results.

\section{FLUORESCEIN ANGIOGRAPHY}

With fluorescein angiography 11 of 30 cases of melanoma were classified correctly $(36 \cdot 6 \%)$; in 19 cases of melanoma fluorescein angiograms were qualified as a 'possible melanoma' (Table 3). In one patient an initial fluorescein angiogram gave diagnosis as 'possible melanoma', while a fluorescein angiogram taken 2 years later a qualified as melanoma. With regard to tumour size three of five T1 tumours were classified

Table 1 Detection rate of choroidal melanoma with planar scintigraphy and single photon emission tomography (SPET) in relation to tumour size

\begin{tabular}{llll}
\hline & \multicolumn{3}{l}{ Tumour size } \\
\cline { 2 - 4 } & $T 1$ & $T 2$ & $T 3$ \\
\hline Detection scintigraphy & $1 / 5(20 \%)$ & $5 / 16(31 \%)$ & $15 / 21(71 \%)$ \\
Detection SPET & $1 / 1$ & $2 / 7(29 \%)$ & $6 / 9(67 \%)$ \\
\hline
\end{tabular}

Table 2 Ultrasonography in 42 melanoma patients

\begin{tabular}{llll}
\hline & Diagnosis & & \\
\cline { 2 - 4 } Positive & Dubious & Negative \\
\hline $37 / 42$ & $5 / 42$ & $0 / 42$ \\
\hline
\end{tabular}

Table 3 Fluorescein angiography in 30 melanoma patients

\begin{tabular}{llll}
\hline & Diagnosis & & \\
\cline { 2 - 4 } Positive & Dubious & Negative \\
\hline $11 / 30$ & $19 / 30$ & $0 / 30$ \\
\hline
\end{tabular}

Table 4 Diagnosis with ultrasonography and fluorescein angiography in relation to tumour size

\begin{tabular}{llll}
\hline & \multicolumn{3}{l}{ Tumour size } \\
\cline { 2 - 4 } & $T 1$ & $T 2$ & $T 3$ \\
\hline $\begin{array}{l}\text { Correctly diagnosed } \\
\text { with ultrasonography }\end{array}$ & $3 / 5(60 \%)$ & $14 / 16(88 \%)$ & $20 / 21(95 \%)$ \\
$\begin{array}{c}\text { Correctly diagnosed } \\
\text { with fluorescein } \\
\text { angiography }\end{array}$ & $3 / 5(60 \%)$ & $8 / 14(57 \%)$ & $0 / 10(0 \%)$ \\
\hline
\end{tabular}

,


Table 5 Immunoscintigraphy and immunohistochemistry in 22 melanomas

\begin{tabular}{lllllcll}
\hline $\begin{array}{l}\text { Patient } \\
\text { No }\end{array}$ & Sex/age & Scintigraphy & $\begin{array}{l}\text { PA } \\
\text { diagnosis }\end{array}$ & Size & Expression & $\begin{array}{l}\text { Intensity of } \\
\text { stainingt }\end{array}$ & $\begin{array}{c}\text { Vessel } \\
\text { staining }\end{array}$ \\
\hline 1 & F 58 & - & spindle & T3 & 80 & \pm & \pm \\
2 & M 74 & - & spindle & T1 & 100 & \pm & \pm \\
3 & F 66 & + & mixed & T3 & 90 & \pm & \pm \\
4 & M 41 & + & mixed & T2 & 80 & \pm & \pm \\
5 & M 65 & + & epitheloid & T3 & 90 & \pm & + \\
6 & M 76 & - & epitheloid & T3 & 5 & \pm & + \\
7 & F 56 & + & mixed & T3 & 100 & \pm & + \\
8 & M 76 & + & spindle & T3 & 90 & \pm & + \\
9 & M 68 & - & mixed & T3 & 60 & \pm & ++ \\
10 & M 65 & - & spindle & T3 & 70 & \pm & \pm \\
11 & M 75 & - & mixed & T2 & 70 & \pm & \pm \\
12 & F 64 & + & mixed & T3 & 80 & \pm & \pm \\
13 & F 65 & - & mixed & T2 & 100 & \pm & \pm \\
14 & F 69 & + & mixed & T3 & $0 \star \star$ & \pm & \pm \\
15 & M 52 & + & mixed & T3 & 70 & \pm & \pm \\
16 & M 74 & + & mixed & T3 & 80 & \pm & \pm \\
17 & F 62 & - & mixed & T3 & 80 & \pm & \pm \\
18 & F 44 & + & mixed & T3 & 5 & \pm & \pm \\
19 & F 70 & + & spindle & T3 & 90 & + & \pm \\
20 & M 54 & + & spindle & T2 & 70 & \pm & \pm \\
21 & F 72 & + & mixed & T3 & 70 & + & \pm \\
22 & F 38 & + & mixed & T3 & 30 & \pm & \pm \\
\hline
\end{tabular}

^Percentage of cell staining positively.

$\dagger-=$ negative.

$\pm=$ moderate

$+=$ positive.

$++=$ heavy.

$t=$ Not assessable owing to heavy pigmentation or cellular staining.

$\star \star=5 \%$ staining with AEC staining technique.

correctly (60\%), eight of $14 \mathrm{~T} 2$ tumours were classified correctly (57\%), and none of $10 \mathrm{~T} 3$ tumours were classified as melanoma (Table 4). All $10 \mathrm{~T} 3$ tumours were given as 'possible melanoma' according to the fluorescein angiogram. Fluorescein angiography in six patients with a benign intraocular lesion gave a negative result in three cases and 'suspicious' in three cases.

Comparison of the sensitivity of planar scintigraphy and ultrasonography shows a significant difference in favour of ultrasonography for the melanoma cases $(49 \% v 88 \%$, McNemar test $\mathrm{p}<0.0001$ ).

\section{IMMUNOHISTOCHEMISTRY}

Immunohistochemistry in 22 melanoma specimens with DAB staining showed expression of the HMW-MAA in 21 of 22 melanomas (Table 5).

In patient No 14 a large tumour was found showing no expression of melanoma associated antigen but with a positive result on immunoscintigraphy. AEC staining of the tumour in this patient showed expression of MAA in $5 \%$ of the cells which probably caused the positive clinical result.

\section{Discussion}

Planar scintigraphy in the present study showed a detection rate of $49 \%$ in 43 patients with choroidal melanoma which is comparable with results of Scheidler et al. ${ }^{11}$ The use of SPET in 17 patients did not further increase the sensitivity of immunoscintigraphy. This is in contrast with the results of Scheidler $e t a l$ who observed an increase in the sensitivity to $78 \%$ with the use of SPET." In a study of Bomanji et al a sensitivity of $93 \%$ was obtained with the use of SPET but they examined predominantly melanomas of relatively large size. $^{8}$ Average prominence of tumours, detected and not detected with planar scintigraphy, in the present study and in Scheidler's study are comparable $(7.3 v 7.7 \mathrm{~mm}$ and $4.7 v 4.5 \mathrm{~mm}$ ). The only difference between the present study and Scheidler's study is the use of a self made reconstruction programme for SPET acquisition by Scheidler instead of a regular filtering technique which we believe is responsible for the increase in sensitivity. In the present study an increase in sensitivity of immunoscintigraphy was obtained with a double pinhole collimator but the specificity of this instrument turned out to be too low for clinical use.

The results of immunohistochemistry with $\mathrm{MoAb} 225.28 \mathrm{~S}$ in choroidal melanoma tissue show an adequate expression of HMW-MAA. In 19 specimens expression of the HMW-MAA was found in $30 \%$ or more of the tumour cells. We believe that in our series of patients lack of antigen expression does not account for the limited detection obtained with immunoscintigraphy.

Localisation of the tumours in the present study was equally divided over nasal, temporal, peripheral, and central location and was not correlated with detection with SPET. Comparison of the group of tumours detected and not detected with immunoscintigraphy in the present study shows a significant difference in both tumour prominence and tumour diameter between both groups $(p<0.0008)$, as was also found by Scheidler et al. ${ }^{11}$ This confirms tumour size as being a significant parameter for detectability in scintigraphy.

Planar scintigraphy and SPET showed a $87 \%$ specificity in eight control patients. Increased activity was seen twice in the fellow eye of a patient with a benign intraocular lesion, once with SPET, and once with planar scintigraphy. This further limits the value of immunoscintigraphy in choroidal melanoma.

Ultrasonography showed a high detection rate of choroidal melanoma in the present study $(88 \%)$ without false positive or negative results. This leaves ultrasonography, at present, as the most reliable ancillary test for the diagnosis of choroidal melanoma.

Fluorescein angiography showed a correct positive diagnosis of choroidal melanoma in $30 \%$ of the patients. Positive results with fluorescein angiography were found in $\mathrm{T} 1$ and $\mathrm{T} 2$ classified tumours - that is, smaller tumours. This indicates the usefulness of fluorescein angiography in the diagnosis of choroidal melanoma since, particularly in small melanomas, the assessment of the diagnosis can be difficult.

Recently, cases of scintigraphic detection of choroidal melanoma with 123 iodoamphetamine and $\quad N$-isopropyl- $p$-I123-iodoamphetamine, which spreads into regions of melanin production, were reported. ${ }^{12}{ }^{13}$ Initial results with a new radioactive tracer $\mathrm{N}$-(2-diethylaminoethyl)4iodobenzamide showed a detection rate of $94 \%$ in 16 patients with melanoma ${ }^{14}$ but tumour prominence is not mentioned in this study. Recently, a report on radioimmunoscintigraphy with technetium labelled MoAb 225.28S in 15 choroidal melanomas was published, showing a $100 \%$ detection rate but without data on tumour size. ${ }^{15}$ Efforts are being made to improve the results in 
immunoscintigraphy such as an increase of the tumour/background ratio by means of a three step labelling procedure used in cutaneous melanoma and other tumours ${ }^{16}$ or the use of a diester linkage between chelate and antibody. ${ }^{17}$

Latest results of the Collaborative Ocular Melanoma Study in the United States show false positive results in only $0.5 \%$ of melanoma patients ${ }^{18}$ indicating that the diagnosis of choroidal melanoma in a clinical centre with regular diagnostic modalities is accurate. At present the main limitation of scintigraphy in choroidal melanoma is the limited tumour size although a computed reconstruction programme for SPET reconstruction may increase the detection rate of immunoscintigraphy. Since small tumours present most difficulties in diagnosis, immunoscintigraphy is at present not a valuable diagnostic technique for small choroidal lesions.

We thank Dr Bleeker for providing numerous patient data; Dr K Zwinderman, $\mathrm{PhD}$, for performing statistical analysis; $\mathrm{Dr}$ Keunen, $\mathrm{PhD}$, and $\mathrm{Dr}$ Mourits, $\mathrm{PhD}$, for critically reading the manuscript.

1 Ossoinig KC, Harrie RP. Diagnosis of intraocular tumors with standardized echography. In: Lommatzsch PK, Blodi FC eds. Intraocular tumors. Berlin: Springer Verlag, 1983: 154-75.

2 Kohler G, Milstein C. Continuous cultures of fused cells secreting antibody of predefined specificity. Nature 1975 ; 256: 495 .

3 Bomanii J, Garner A, Prasad J, Albert DM, Hungerford JL Granowska $M$, et al. Characterisation of ocular melanoma wranowska M, et al. Characterisation of ocular melanoma with cutaneous

4 Van der Pol JP, Jager MJ, De Wolff-Rouendaal D, Ringens PJ, Vennegoor C, Ruiter DJ. Heterogenous expression of melanoma-associated antigens in uveal melanomas. Curr Eye Res 1987; 6: 757-65.

5 Harmer MH, Oosterhuis JA. TNM classification of ophthalmic tumours. Geneva: International Union against Cancer, 1985.

6 Gass JDM. Fluorescein angiography: an aid in the differential diagnosis of intraocular tumors. Int Ophthalmol Clin 1972; 12: 85 .

7 Schaling DF, Van Kroonenburg MJPG, Borsje RA, Camps JAJ, Kakebeeke-Kemme HM, Oosterhuis JA, et al. Radioimmunoscintigraphy with melanoma associated monoclonal antibody fragments in ocular melanoma. Graefes Arch Clin Exp Ophthalmol 1989; 227: 291-4.

8 Bomanji J, Nimmon CC, Hungerford JL, Solanki K, Granowska $M$, Britton KE. Ocular radiommunoscintigraphy: sensitivity and practical considerations $\mathcal{F}$ Nucl Med 1988; 29: 1038-44.

9 Scheidhauer K, Markl A, Leisinger G, Moser E, Scheiffarth $\mathrm{OF}$, Riedel KG, et al. Immunoscintigraphy in intraocular malignant melanoma. Nucl Med Comm 1988; 9: 669-79.

10 Schaling DF, Van der Pol JP, Jager MJ, Van Kroonenburgh MJPG, Oosterhuis JA, Ruiter DJ. Radioimmunoscintigraphy and immunohistochemistry with melanoma associated monoclonal antibodies in choroidal melanoma: comparison of the clinical and immunohistochemical results. Brf Ophthalmol 1990; 74: 538-41.

11 Scheidler J, Leinsinger G, Kirsch CM, Scheiffarth OF, Stefani FH, Riedel KG. Immunoimaging of choroidal melanoma: FH, Riedel KG. Immunoimaging of choroidal melanoma: assessment of its diagnostic accuracy and

12 Ono S, Fukunaga M, Otsuka N, Nagai K, Morita K, Furukawa $\mathrm{T}$, et al. Visualisation of ocular melanoma with $\mathrm{N}$-isopropyl-p-123I-iodoamphetamin. F Nucl Med 1988; 29: 1448-50.

13 Dewey SH, Leonard JC. Ocular melanoma: detection using iodine 123-iodoamphetamine and SPECT imaging. $7 \mathrm{Nucl}$ Med 1990; 31: 375-7.

14 Bacin F, Bonafous J, Michelot J, Moreau MF, Madelmont JC, Veyre A. Clinical study of a new iodine-123 radiopharmaceutical (Benzamide) in the diagnosis of ocular malignant melanoma. Vienna: Meeting Club Jules Gonin, Sept, 1992.

15 Feggi L, Indelli M, Pansini GC, Santini A, Prandini N, Virgili AR. Immunoscintigraphy in malignant melanoma: a fiveyear clinical experience. Nucl Med Comm 1993; 14: 145-8.

16 Paganelli G, Magnani P, Zito F, Villa E, Sudati F, Lopalco L, et al. Three-step monoclonal antibody tumor targeting in carcinombryonic antigen positive patients. Cancer Res 1991; 51: 5960-6.

17 Paik CH Yokoyama K, Reynolds JC, Quadri SM, Min CY, Shin SY, et al. Reduction of background activities by introduction of a diester linkage between antibody and a chelate in radioimmunodetection of tumor. $\mathcal{F ~} \mathrm{Nucl}$ Med 1989; 30: 1693-701.

18 The Collaborative Ocular Melanoma Study Group. Accuracy of diagnosis of choroidal melanomas in the collaborative ocular melanoma study. Arch Ophthalmol 1990; 108: 1268-73. 